\title{
Impact of regulatory assessment on clinical studies in Brazil
}

\author{
luis Augusto Tavares Russo ${ }^{1 *}$, Freddy Goldberg Eliaschewitz ${ }^{2}$, Vitor Harada ${ }^{3}$, Roberta Pereira Trefiglio ${ }^{4}$, \\ Raffaella Picciotti ${ }^{5}$, Paula Goulart Pinheiro Machado ${ }^{6}$, Gustavo Luiz Ferreira Kesselring ${ }^{7}$ \\ ${ }^{1} \mathrm{PhD}$ - Director of Centro de Pesquisas e Análises Clínicas (CCBR), Rio de Janeiro, RJ, Brazil \\ ${ }^{2} \mathrm{MD}$, Researcher - Director of Centro de Pesquisas Clínicas. President of the Medical Research Committee of Sociedade Brasileira de Endocrinologia e Metabolismo (SBEM), São Paulo, SP, Brazil \\ ${ }^{3} \mathrm{MD}$ - Pharmacist and Lecturer of the Medical Research Graduate Program at Faculdade de Ciências Médicas da Santa Casa de São Paulo. Director of Quintiles, São Paulo, SP, Brazil \\ ${ }^{4}$ Pharmacist and MSc in Health Economics - Partner/Owner of Idealclinops - Advisory services in Medical Research and Pharmacoeconomics, São Paulo, SP, Brazil \\ ${ }_{5}^{5}$ Pharmacist and MBA - Medical Integrated Hospital and Intensive Care Division at Novartis Pharmaceuticals, São Paulo, SP, Brazil \\ ${ }^{6} \mathrm{MD}$, PhD and MBA. Head of the Medical Integrated Hospital and Intensive Care Division at Novartis Pharmaceuticals, São Paulo, SP, Brazi \\ ${ }^{7} \mathrm{MD}$ - Director of Instituto Vis Research. Member of the Board, Sociedade Brasileira de Medicina Farmacêutica. Representative of Associação Médica Brasileira, São Paulo, SP, Brazil
}

Study conducted at Aliança Pesquisa Clínica Brasil, Rio de Janeiro, RJ, Brazil

Article received: $6 / 2 / 2015$ Accepted for publication: 6/21/2015

*Correspondence: Address: Av. Dr. Chucri Zaidan, 920 $9^{\circ}$ andar

São Paulo, SP - Brazi Postal code: 04583-904 tatiana.azeredo@ccbr.com

http://dx.doi.org/10.1590/1806-9282.62.05.447

\section{SUMmARY}

Introduction: Despite the recent expansion of clinical studies allocated to Brazil, the delay of local regulatory deadlines directly impacts their completion.

Objective: This article examines the allocation process of clinical studies to Brazil in comparison with other countries, as well as the financial impact of studies not completed due to interruption caused by the delay in the regulatory process. Method: The allocation processes of studies were compared in nine countries with similar stages of economic development and countries in Latin America using the websites http://data.worldbank.org/data-catalog/GDP-rankings-table and http://worldpopulationreview.com and clinicaltrials.gov, comprising 185 countries. The 46 studies sponsored by the pharmaceutical industry underwent an analysis of the regulatory review process.

Results: 46 studies sponsored by the industry and submitted in the country between June 2007 and June 2013 were analyzed; 18 (39\%) were discontinued due to the delay in obtaining the necessary approvals. For the approved studies, patient recruitment began an average of 11 months after the other countries. It is estimated that 530 Brazilians patients did not have the opportunity to participate in these studies. Financial losses were to the order of 14.6 million dollars for the country, including patient, medication and supplies costs, and expenses.

Conclusion: Brazil has enormous potential for the realization of clinical studies. Researchers, associations of disabled people and patients with chronic diseases, sponsors and the authorities must work together to develop an approval process that is efficient, predictable and, most of all, transparent. The current regulatory environment must and can be improved and optimized in order to result in tangible benefits for patients, society and the country's scientific development.

Keywords: ethics, clinical protocols, impact on health.

\section{INTRODUCTION}

Brazil is the largest country in Latin America with impressive socioeconomic indicators. In 2013, the population was estimated at 200 million people (the $5^{\text {th }}$ largest country in the global ranking) ${ }^{1}$ with gross domestic product (GDP) of USD 2,245,673 ( $7^{\text {th }}$ place in the global ranking). ${ }^{2}$ In 2012, the Brazilian pharmaceutical market was the $6^{\text {th }}$ largest in the world, totaling USD 29,112 million in sales. ${ }^{3}$

In addition to being a favorable economic environment with a solid culture in regulations in accordance with good clinical practices, Brazil has researchers and teams that are well trained and prepared. Clinical research centers have attracted important international investments in the last decade, that in part resulted in the amount of clinical studies allocated to the country: 16 phase 2 and 3 studies were sponsored by the industry in 2002 compared with 103 studies in 2013, which is a 540\% increase. $^{4}$

The regulatory process for the implementation of a clinical study in Brazil requires assessment and approv- 
al in two instances at the Ministry of Health: an ethical approval by the National Commission of Research Ethics (Comissão Nacional de Ética em Pesquisa, CONEP) and logistics approval by the National Health Surveillance Agency (Agência Nacional de Vigilância Sanitária, ANVISA). In practice, two ethics committees - one institutional (Research Ethics Committee - Comitê de Ética em Pesquisa, CEP) and one national (CONEP) - approve the same documentation.

Ethical approval is a process with various stages. In the first stage, a coordinating research center must be selected and the study protocol and related documents must be approved by the CEP of that center, certified by the CONEP. Next, the regulatory documentation already approved by the CEP of the coordinating center must be forwarded for approval by the CONEP. Once final approval is granted, in the case of multicenter studies, all documentation must be presented to the CEP of each research center. In other words, two Ethics Committees - institutional and national - approve the same documentation. ${ }^{5}$

For the assessment by ANVISA, the sponsor of the study should provide a description of the study, as well as related supplies (medication, lab kits, and equipment). After approval it is also necessary to obtain an import permit for the supplies needed to start the study. Additionally, a new license must be obtained for each import. It is interesting to point out that in other countries there is only one ethical approval stage, versus the two stages in Brazil (CEP and CONEP) for multicenter studies. ${ }^{6}$

Although there has been a notable expansion in the number of studies allocated to Brazil in recent years, its effective participation is not guaranteed as the time for obtaining all regulatory approvals is unpredictable. Suspension of the approval process is not uncommon in the country after the end of recruitment of study in other countries, which are more efficient in obtaining the required approvals. It should be noted that in the long process for conducting clinical trials sponsored by the industry, accounting for around $62 \%$ of clinical research, the allocation of such studies to various countries is an essential stage where management teams select countries and regions able to meet aggressive recruitment deadlines, providing not only high quality data, but respecting the regulatory environment to ensure patient protection.? $^{\text {? }}$

Finally, in January 2012 a new electronic submission process was initiated in Brazil, the "Brazil Platform", developed by the Federal Government to receive research projects from CEPs across the country. This tool replaced the National Information System on Ethics in Research involving Human Beings (SISNEP), with the initial objective of providing greater safety for the registration and monitoring of research. This study aims to analyze the allocation of studies in Brazil in comparison with other countries considered relevant, and to assess the impact of the regulatory process on completion of such studies, including the loss of investment in the country.

\section{Method}

Study allocation

For the purpose of comparing the study allocation process, nine countries were selected:

- $\quad$ BRIC countries: Brazil, Russia, India and China with a similar stage of economic development;

- Latin American countries: Argentina and Mexico with similar political and cultural aspects.

Basic socioeconomic indexes (GDP in 2012, population in 2013) were obtained from websites accessible to the public (http://data.worldbank.org/data-catalog/GDP-rankings-table and http://worldpopulationreview.com); the number of clinical studies was obtained from the website clinicaltrials.gov, which includes general information about medical studies with human volunteers in 185 countries. ${ }^{4}$ With access available to the public in February 2000, the registration requirements on clinicaltrials.gov were expanded in 2007 in accordance with the amendments to the Food and Drug Administration (FDA) Act of 2007. Based on these changes, we chose data from 2007 onwards for this comparison. To assess the allocation among countries where phase 2 and 3 clinical studies sponsored by industry took place, two 12 months periods were assessed: $01 / 01 / 2012$ to $12 / 31 / 2012$ versus $01 / 01 / 2007$ to $12 / 31 / 2007$. No significant variations were observed from 2008 to 2011 that could cause any bias in this analysis.

\section{Overview of the regulatory approval process and financial impact}

We analyzed 46 studies sponsored by the industry with the regulatory approval process starting between June 2007 and June 2013: 28 (61\%) were successfully approved and $18(39 \%)$ studies were interrupted during the regulatory process due to the conclusion of patient recruitment by other countries.

For the 28 studies approved in Brazil, the periods of approval by the CEP, CONEP and ANVISA were analyzed. The date of the first patient included in the study in Brazil in relation to the rest of the world was also assessed. 
For canceled studies, the financial loss was estimated based on the budget originally planned for these projects:

- Patient costs: procedures reimbursed to the research center, researcher or team for conducting visits, study procedures and complementary examinations. The estimated amounts were based on an average of the Brazilian values, except for the laboratory tests that were calculated at 2.5 times the standard price of the Brazilian Medical Association's recommendation list;

- Medication costs: costs directly related to the price of medication during the study period;

- Study supplies: equipment-related costs, import taxes and logistics for distribution of drugs;

- Administrative expenses: costs related to translation and revision of documentation for submission of the protocol, fees etc.

\section{Results}

\section{Study allocation}

As the Gross Domestic Product (GDP) was used as one of the criteria for the selection of countries, it is not surprising that most of the countries analyzed report similar GDPs (with China and Argentina as exceptions in this example).

According to the data available on clinicaltrials.gov, a total of 2,777 phase 2-3 studies sponsored by the industry were carried out worldwide in 2012, a decline of
$15 \%$ compared to $2007(n=3,292)$. For the BRIC countries, despite the total variation for the group of countries being almost zero, there is a marked difference between the increases in Russia (11.7\%) and China (51.1\%) compared to the reductions noted in Brazil (11.7\%) and India (54.7\%). On the other hand, Argentina (135) and Mexico (136) maintained their participation with about 30\% more studies than Brazil (106) in 2012 (Table 1). Additionally, compared to Argentina and Mexico, Brazil presents a significantly lower density of clinical studies (number of studies divided by the estimated population in millions).

Overview of the regulatory approval process and financial impact in Brazil

The data relating to regulatory approval times were only considered for the 28 studies approved. The average for approval in the CEP was 46 days (7-248 days) with a substantial increase in deadlines for CONEP (175 days; 62-362 days) and ANVISA (168 days; 9-328 days), adding an average of 6 months to the regulatory approval process. Compared to other countries, our time for obtaining approval leads the country to start recruiting patients (first visit by the first patient - FPFV) an average of 11 months (328 \pm 120 days) after the other countries (Table 2). Based on the domestic data obtained, other countries are ready to start recruiting 120 days after receiving the documentation to begin the regulatory process.

\section{TABLE 1 Comparison of the allocation of clinical trials in 2012 versus 2007.}

\begin{tabular}{|c|c|c|c|c|c|c|c|}
\hline \multirow[t]{2}{*}{ Country } & \multirow[t]{2}{*}{ GDP (ranking) ${ }^{a}$} & \multirow[t]{2}{*}{ Population estimates (ranking) ${ }^{b}$} & \multicolumn{3}{|c|}{ Number of studies ${ }^{c}$} & \multicolumn{2}{|c|}{ Density of studies ${ }^{d}$} \\
\hline & & & 2007 & 2012 & $2007 \times 2012$ & 2007 & 2012 \\
\hline \multirow[t]{2}{*}{ Brazil } & $2,252,664$ & $200,674,130$ & 120 & 106 & $-11.7 \%$ & 0.60 & 0.53 \\
\hline & $\left(7^{\circ}\right)$ & $\left(5^{\circ}\right)$ & & & & & \\
\hline \multirow[t]{2}{*}{ Russia } & $2,014,776$ & $142,572,794$ & 205 & 229 & $11.7 \%$ & 1.44 & 1.61 \\
\hline & $\left(8^{\circ}\right)$ & $\left(9^{\circ}\right)$ & & & & & \\
\hline \multirow[t]{2}{*}{ India } & $1,841,717$ & $1,210,193,422$ & 161 & 73 & $-54.7 \%$ & 0.13 & 0.06 \\
\hline & $\left(10^{\circ}\right)$ & $\left(2^{\circ}\right)$ & & & & & \\
\hline \multirow[t]{2}{*}{ China } & $8,358,363$ & $1,384,694,199$ & 90 & 136 & $51.1 \%$ & 0.06 & 0.10 \\
\hline & $\left(2^{\circ}\right)$ & $\left(1^{\circ}\right)$ & & & & & \\
\hline \multirow[t]{2}{*}{ Mexico } & $1,117,956$ & $122,730,392$ & 134 & 136 & $1.5 \%$ & 1.09 & 1.11 \\
\hline & $\left(14^{\circ}\right)$ & $\left(11^{\circ}\right)$ & & & & & \\
\hline \multirow[t]{2}{*}{ Argentina } & 470,533 & $41,499,700$ & 142 & 135 & $-4.9 \%$ & 3.42 & 3.25 \\
\hline & $\left(26^{\circ}\right)$ & $\left(32^{\circ}\right)$ & & & & & \\
\hline
\end{tabular}

GDP: Gross Domestic Product;

aData presented in millions of US dollars for 2012, available from http://databank.worldbank.org/data/download/GDP.pdf.

'Estimated data for 2013, with the exception of India (2011), available from http://worldpopulationreview.com/countries/.

'Data from http://clinicaltrials.gov (phase 2-3 studies sponsored by the industry), total of 3,292 studies (2007) and 2,777 studies (2012

dDensity of studies: number of studies divided by the estimated population. 
TABLE 2 Deadlines for approval of clinical studies successfully conducted in Brazil.

\begin{tabular}{llllll} 
Days & Total & CEP & CONEP & ANVISA & FPFV \\
\hline Mean & 378 & 46 & 175 & 168 & 328 \\
\hline Median & 358 & 35 & 159 & 144 & 303 \\
\hline SD & 96 & 46 & 83 & 87 & 120 \\
\hline Min-Max & $256-587$ & $7-248$ & $62-362$ & $9-328$ & $170-609$ \\
\hline
\end{tabular}

CEP: Research Ethics Committee; CONEP: National Research Ethics Commission; ANVISA: National Health Surveillance Agency; FPFV: first patient, first visit; SD: standard deviation; Min: Minimum; Max: Maximum.

For the 18 studies canceled, the deadlines are much larger and could not be assessed due to cancellation before completion of the regulatory process. Based on the available data, 10 months (296 \pm 88 days) was the average time between the first submission to the CEP until the final decision to cancel the study in Brazil, as all the other countries had already finished recruiting patients.

It is estimated that at least 530 Brazilian patients did not have the opportunity to participate in these 18 clinical trials in various therapeutic areas (Table 3 ) given that most of the studies are competitive. The estimated financial losses are to the order of 14.6 million dollars for the country, including patient costs, medication, supplies and administrative expenses. On average, each patient repre- sents a cost of USD 27,500 per capita or about USD 811,700 per study. It is worth mentioning that this analysis did not include the costs effectively borne by the Brazilian health system with such patients during this period.

If we consider the potential growth for the country in terms of the number of clinical studies in accordance with that observed (2007 versus 2012) for the BRIC countries, Brazil could potentially have conducted 40 additional clinical studies (106 conducted versus 146 forecast), which would represent an estimated loss of USD 32.5 million. If the comparison was made with other Latin American countries, 30 additional studies could have been allocated to Brazil (106 conducted versus 136 forecast) with estimated losses of USD 24.3 million.

\section{Discussion}

The introduction of a new drug on the market is a long process lasting 10 to 15 years. On average, only five in every 5,000 to 10,000 compounds analyzed begin the clinical trials phase, with only one approved. ${ }^{8,9}$ It is estimated that two in every ten medications commercialized create revenues that exceed those of research and development $(\mathrm{R} \& \mathrm{D})$ costs. ${ }^{10}$ Considering that indicated above and the fact that since 2000 pharmaceutical companies

TABLE 3 Financial losses from canceled studies (currency = USD).

\begin{tabular}{|c|c|c|c|c|c|c|}
\hline Study & $\begin{array}{l}\text { Planned number of } \\
\text { patients }\end{array}$ & Patient costs & Medication costs & Study supplies & $\begin{array}{l}\text { Administrative } \\
\text { expenses }\end{array}$ & Total \\
\hline 1 & 20 & 62,228 & 488 & 34,323 & 41,958 & 138,997 \\
\hline 2 & 70 & 335,648 & 31,012 & 28,149 & 30,274 & 425,083 \\
\hline 3 & 15 & 151,127 & 225 & 26,627 & 41,320 & 219,298 \\
\hline 4 & NA & NA & 21,383 & 11,802 & 15,865 & 49,050 \\
\hline 5 & 30 & 299,798 & 969,228 & 511,097 & 65,866 & $1,845,989$ \\
\hline 6 & 55 & 472,025 & 195,826 & 304,927 & 61,946 & $1,034,724$ \\
\hline 7 & NA & NA & $1,785,714$ & 625,000 & 65,374 & $2,476,089$ \\
\hline 8 & 32 & 391,393 & $1,009,042$ & 579,437 & 75,139 & $2,055,010$ \\
\hline 9 & 15 & 88,231 & 4,406 & 55,429 & 41,441 & 189,507 \\
\hline 10 & 24 & 194,532 & 107,143 & 104,531 & 147,925 & 554,130 \\
\hline 11 & 24 & 208,754 & 107,143 & 111,931 & 147,925 & 575,753 \\
\hline 12 & 40 & 286,588 & 85,714 & 68,981 & 53,150 & 494,434 \\
\hline 13 & 30 & 236,730 & 102,885 & 97,499 & 32,450 & 469,564 \\
\hline 14 & 20 & 183,608 & 22,773 & 45,441 & 48,249 & 300,071 \\
\hline 15 & 30 & 810,042 & 48,407 & 38,068 & 49,665 & 946,182 \\
\hline 16 & 80 & 838,600 & 107,143 & 135,667 & 58,925 & $1,140,334$ \\
\hline 17 & 30 & 731,057 & 313,043 & 149,896 & 55,033 & $1,249,029$ \\
\hline 18 & 15 & 187,342 & 111,801 & 87,000 & 61,043 & 447,187 \\
\hline Total & 530 & $5,477,703$ & $5,023,377$ & $3,015,803$ & $1,093,548$ & $14,610,430$ \\
\hline
\end{tabular}

*Exchange rate based on the annual value established by the company, varying according to the year that the regulatory process of the study began; ** Low medication costs are due to the value established by the global team for selling medication to countries at the time of the allocation of the study; NA: not available for analysis. 
have invested more than half a trillion dollars in $R \& D$, including an estimated 51.1 billion dollars in $2013,,^{1-3,11}$ there must be efficient mechanisms for managing the process of high-risk drug development. ${ }^{12}$

It is indisputable that the ethical review of research involving human beings is essential for protecting the rights and safety of research subjects, while also promoting socially beneficial research and protecting research subjects from harm and indignity, maintaining trust between researchers and society. ${ }^{5,13,14}$ However, in practice, the current process in Brazil is not only time consuming, requiring duplication of effort by researchers, Ethics Committees (institutional and national), ANVISA and sponsors, but also deprives the Brazilian population and researchers from participating in innovative clinical studies involving new drugs and also medical devices and equipment not yet employed in the country.

In 2008, an independent report prepared by the clinical research community had already indicated structural and operational problems that have prevented Brazil from obtaining good results in clinical research. At that time, certain measures, such as the complete decentralization of the CEP-CONEP system for multicenter studies with foreign participation, adoption of a single assessment system, tacit approval, as well as the elimination of the requirement to submit a document for approval in the country of origin, had already been proposed to improve the system, ${ }^{7}$ although nothing was implemented.

The double ethical approval (CEP and CONEP) for phase 1-3 studies or any clinical study involving foreign co-participation required by the Ministry of Health in Brazil is one of the stages that cause the most delays in the regulatory approval process. It is noteworthy that this legislation is not in line with other countries in Latin America and worldwide, which require only one ethical assessment stage.

Considering that Brazil starts recruiting patients an average of 328 days after other countries, it is clear that several additional patients could have participated in the clinical studies carried out in the country if there had been more time for recruitment. Christie et al. assessed the impact of the delay in the approval process in a cancer study in Australia and concluded that, in the final analysis, a 2 month delay in this process could be responsible for 60 avoidable deaths from cancer per year. Although not all clinical studies can save lives, each patient for whom participation in a clinical study is prevented as a result of these delays misses a significant opportunity to receive access to innovative treatments. ${ }^{15}$ The ethical review was developed to ensure the protection of patients, but this precept is not always observed. As an example we can cite the ISIS- 2 study on acute myocardial infarction, where the comparison between the requirements necessary in the USA and United Kingdom in the ICF of participants estimated around 10,000 unnecessary patient deaths attributed to factors that reduced recruitment. ${ }^{16}$

Eighteen (39\%) of the 48 studies analyzed were canceled during the approval process due to impractical deadlines noted with the CONEP, ANVISA or both, emphasizing the country's inefficiency to compete in the clinical research environment. It should be noted that not only were none of these studies "purely" placebo-controlled but also the sponsor had agreed to provide assistance and medication after the completion of the study to all patients, as required by local regulations. In other words, the issues that are commonly subject to discussion in the study approval process were properly addressed. This shows a process that makes it increasingly difficult to conduct international clinical studies sponsored by the industry in Brazil. Even so, in studies in which Brazilian researchers obtain regulatory approval before the end of recruitment, the country presents excellent performance, including a significant number of patients in record time, showing the high capacity of clinical research centers in Brazil. ${ }^{17-19}$ It is estimated that these 18 studies alone represent a loss of financial investment of more than 14.6 million dollars. The financial losses are even more dramatic if we take into account other countries with similar geographical, cultural or economic features as the basis for potential studies that might have been allocated to Brazil: USD 32.5 million compared to the BRIC countries and USD 24.3 million compared to Latin America.

The latest preliminary assessment after implementation of the "Brazil Platform" shows that there are still shortcomings, as there was a significant increase in the regulatory deadlines, especially at ANVISA. According to ABRACRO (the Brazilian Association of Representative Organizations of Clinical Research) only 12 (14\%) of the 85 protocols recently submitted (Jan/2013 to Mar/2014) to the CONEP and ANVISA, which would benefit around 4,971 patients and many researchers, have already been approved by both organizations. Additionally, during the same period, the CONEP was able to evaluate $30 \%$ more studies than ANVISA. ${ }^{20}$ This recent analysis may still reflect a continuous process of adapting to the new electronic tool, which could improve over time. However, not only training remains necessary, but also the implementation of important changes in order to make the platform more flexible, user-friendly and transparent to all the parties involved, including the public. 
Unfortunately, in view of all the foregoing, clinical studies management teams currently only accept and commit to participate in projects with a large numbers of patients and long recruitment periods (more than 9 months at least), making the country a non-competitive environment in the clinical research scenario. Indeed, this impact can already be seen from the analysis of the number of studies that could potentially have been conducted across the country compared to the performance observed in other Latin American and BRIC countries.

Finally, there are some further important points to consider. In addition to the fact that the results of studies conducted in high-income countries with different characteristics compared to those in our country may not always be repeatable within the Brazilian population, it is essential for Brazilian researchers to have the opportunity to contribute to the discussion and design of clinical studies in which they participate, as many renowned Brazilian researchers have been invited to contribute to national and multinational clinical research protocols.

In addition to the actual measurable financial losses, there is also an important impact on the country's "image": Brazil is becoming a more and more difficult country for working with clinical research. In the opposite direction, Russia, China and India have been working in close collaboration with the European Medicines Agency (EMA), instituting similar standards of approval and management of studies, ${ }^{21}$ and thereby making them more attractive for the allocation of studies.

Several actions could be implemented to speed up the process: given that the CEPs are certified by the CONEP, they should have the autonomy to approve studies without the endorsement of the latter. In addition, issues related to the informed consent form and other are recurrent. This point has sparked countless discussions and the eventual withdrawal of certain industries and access to medication after the study, which would certainly diminish efforts and optimize the deadlines for approval. The proposed amendments already indicated in $2008^{7}$ still remain the main factors to promote a change in the current scenario in Brazil.

Several civilian organizations such as patient associations, the Brazilian Medical Association (AMB), the Brazilian Society of Pharmaceutical Medicine (SBMF), Interfarma, as well as the recently created Clinical Research Alliance of Brazil ${ }^{22}$ are united in initiatives to improve the regulatory scenario in Brazil.

\section{Conclusion}

Brazil has an enormous potential for the conduction of clinical trials. Researchers, associations of disabled peo- ple and patients with chronic diseases, sponsors and the authorities must work together to develop an approval process that is efficient, predictable and, most of all, transparent. The current regulatory environment must and can be improved and optimized in order to achieve tangible benefits for the patients, society and the medical/ scientific development of the country.

\section{Resumo}

Impacto da avaliação regulatória em estudos clínicos no Brasil

Introdução: apesar da recente expansão de estudos clínicos alocados para o Brasil, a demora dos prazos regulatórios locais impacta diretamente em sua realização. Objetivo: este artigo analisa o processo de alocação de estudos clínicos para o Brasil em comparação a outros países, bem como o impacto financeiro dos estudos não realizados em decorrência da interrupção pela demora no processo regulatório.

Método: foram comparados os processos de alocação de estudos em nove países com estágios semelhantes de desenvolvimento econômico e países da América Latina através dos sites http://data.worldbank.org/data-catalog/ GDP-ranking-table, http://worldpopulationreview.com e clinicaltrials.gov, que engloba 185 países. Os 46 estudos patrocinados pela indústria farmacêutica tiveram o processo de avaliação regulatória analisado.

Resultados: foram analisados 46 estudos patrocinados pela indústria submetidos no país entre junho de 2007 e junho de 2013; 18 (39\%) foram descontinuados pelo atraso na obtenção das aprovações necessárias. Para os estudos aprovados, o recrutamento de pacientes começou, em média, aos 11 meses após os demais países. Estima-se que 530 pacientes brasileiros não tiveram a oportunidade de participar desses estudos. As perdas financeiras foram da ordem de 14,6 milhões de dólares para o país, incluindo custos com paciente, medicação, suprimentos e despesas administrativas. Conclusão: o Brasil tem um enorme potencial para a realização de estudos clínicos. Investigadores, associações de deficientes e pacientes portadores de doenças crônicas, patrocinadores e autoridades devem trabalhar juntos para desenvolver um processo de aprovação eficiente, previsível e antes de tudo transparente. $\mathrm{O}$ atual ambiente regulatório deve e pode ser melhorado e aperfeiçoado, caso contrário não resultará em benefícios tangíveis para o paciente, para a sociedade e a evolução médico-científica do país.

Palavras-chave: ética, protocolos clínicos, impactos na saúde. 


\section{REFERENCES}

1. World Population Review [cited 2013 Nov 21]. Available from: http:// worldpopulationreview.com.

2. The World Bank Group. GDP ranking [cited 2013 Nov 21]. Available from: http://data.worldbank.org/data-catalog/GDP-ranking-table.

3. The Association of the British Pharmaceutical Industry. Global pharmaceutical industry and market [cited 2013 Nov 21]. Available from: http://www.abpi. org.uk/industry-info/knowledge-hub/global-industry/Pages/industry-marketaspx\#fig2.

4. U.S. National Institutes of Health. ClinicalTrials.gov [cited 2013 Nov 21] Available from: http://clinicaltrials.gov.

5. Resolução 196/96 do Conselho Nacional de Saúde - Ministério da Saúde.

6. Ezzat H, Ross S, von Dadelszen P, Morris T, Liston R, Magee LA; CPN Collaborative Group. Ethics review as a component of institutional approval for a multicentre continuous quality improvement project: the investigator's perspective. BMC Health Serv Res. 2010; 10:223.

7. Ferraz OLM; SBMF. Pesquisa Clínica no Brasil II: Análise crítica do sistema CEP-CONEP e propostas de aperfeiçoamento. Relatório independente. SBMF 2008; 1-18. Available from: http://sbmf.org.br/pdf_temporarios/ artigos/cep_conep.pdf.

8. Petryna A. When experiments travel: clinical trials and the global search for human subjects. New Jersey: Princeton University Press; 2009. ISBN 978-0-691-12656-2.

9. International Federation of Pharmaceutical Manufacturers \& Associations. The Pharmaceutical Industry and Global Health - Facts and Figures 2012 [cited 2014 May 20]. Available from: http://www.ifpma.org/fileadmin/ content/Publication/2013/IFPMA_-_Facts_And_Figures_2012_ LowResSinglePage.pdf.

10. Karamehic J, Ridic O, Ridic G, Jukic T, Coric J, Subasic D, et al. Financial aspects and the future of pharmaceutical industry in the United States of America. Mater Sociomed. 2013; 25(4):286-90.
11. Pharmaceutical Research and Manufactures of America. Available from: http://www.phrma.org/economic-impact\#sthash.I0dGl7OX.dpuf

12. Lockhart MM, Babar Z, Carswell C, Garg S. New Zealand's drug development industry. Int J Environ Res Public Health. 2013; 10(9):4339-51.

13. Hébert P, Saginur R. Research ethics review: do it once and do it well. CMAJ. 2009; 180(6):597-8

14. Beagan B, McDonald M. Evidence-based practice of research ethics review? Health Law Rev.2005; 13(2-3):62-8.

15. Christie DRH, Gabriel GS, Dear K. Adverse effects of a multicentre system for ethics approval on the progress of a prospective multicentre trial of cancer treatment: how many patients die waiting? Intern Med J. 2007; 37(10):680-6

16. Glasziou P, Chalmers I. Ethics review roulette: what can we learn? That ethics review has costs and one size doesn't fit all. BMJ. 2004; 328(7432):121-2.

17. Boonen S, Reginster JY, Kaufman JM, Lippuner K, Zanchetta J, Langdahl B, et al. Fracture risk and zoledronic acid therapy in men with osteoporosis. N Engl J Med. 2012; 367(18):1714-23.

18. Tedesco-Silva H, Kho MM, Hartman A, Vitko S, Russ G, Rostaing L, et al. Sotrastaurin in calcineurin inhibitor-free regimen using Everolimus in de novo kidney transplant recipients. Am J Transplant. 2013; 13(7):1757-68.

19. Saglio G, Kim DW, Issaraglisil S, le Coutre P, Etienne G, Lobo C, et al.; ENESTnd Investigators. Nolitinib versus imatinib for newly diagnosed chronic myeloid leukemia. N Engl J Med. 2010; 362(24):2251-9.

20. Abracro [cited 2014 May 26]. Available from: http://abracro.org.br/images/ relatorio/relatorio-prazos anvisa-e-conep- Julho2014-abracro.pdf.

21. European Medicines Agency [cited 2013 Nov 21]. Available from: http:// www.ema.europa.eu/ema/index.jsp?curl=pages/ partners_and_networks/ document_listing/document_listing_000233. jsp\&mid=WC0b01ac05801f0a04.

22. Aliança Pesquisa Clínica Brasil. Available from: http://www.alianca pesquisaclinica.com.br 